\title{
Hypopituitarism in Wilson's disease resolved after copper-chelating therapy
}

\section{Nina Dauth®1, Victoria T Mücke², Marcus M Mücke², Christian M Lange³ Martin Welker², Stefan Zeuzem² ${ }^{2}$ and Klaus Badenhoop²}

${ }^{1}$ MVZ Diamedicum Würzburg GmbH, Würzburg, Germany, 2Medical Department 1, University Hospital of the Goethe-University Frankfurt, Frankfurt am Main, Germany, and ${ }^{3}$ Clinic for Gastroenterology and Hepatology, University Hospital Essen and University Duisburg-Essen, Essen, Germany
Correspondence should be addressed to N Dauth

Email

dauth@diamedicum.de

\section{Summary}

Wilson's disease (WD) is a rare disorder of copper metabolism usually presenting with variable liver damage and neuropsychiatric symptoms. Here we report a 39-year-old Taiwanese female with late manifestation of WD presenting with gonadotroph, thyreotroph and corticotroph hypopituitarism. Molecular genetic testing revealed compound heterozygosity for two mutations in exons 12 and 14 (c.2828G>A and c.3140A>T). Copper-chelating therapy with D-penicillamine and zinc was initiated along with supplementation of hydrocortisone and L-thyroxine. Hypopituitarism resolved when urinary copper excretion returned to normal levels under copper chelation. This case should raise awareness of pituitary function in WD patients.

\section{Learning points:}

- Hypopituitarism can complicate Wilson's disease (WD) and endocrinologists should be aware of it when caring for hypopituitary patients.

- Hepatologists should consider endocrinologic testing for hypopituitarism when WD patients present with symptoms of adrenal insufficiency, thyroid or gonadal dysfunction.

- Copper-chelating treatment is mandatory and may lead to the recovery of pituitary function in such patients.

\section{Background}

Wilson's disease (WD) is a monogenic copper disorder associated with liver failure and progressive lenticular degeneration. Especially in younger patients, the initial manifestation goes along with acute fulminant liver failure, followed by liver transplantation due to highurgency registration for organ transplant. Hypopituitarism is an exceedingly rare and unusual complication of WD but must be kept in mind when dealing with WD patients especially when unusual symptoms such as hypoglycemia or amenorrhea occur. Diagnosis of hypopituitarism can be challenging since many patients may be asymptomatic or symptoms may be accredited to the underlying liver disease. When hypopituitarism is confirmed, hormone replacement is mandatory according to the extent of pituitary insufficiency. While hypopituitarism is usually irreversible, copper-chelating treatment can facilitate hormonal recovery in WD.

\section{Case presentation \\ Introduction}

Wilson's disease (WD) is a rare monogenetic disorder in which excess copper is deposited mainly in parenchymal organs such as liver and brain. Liver cirrhosis is the most severe complication and often the first obvious clinical manifestation of the disease. Excessive copper 
accumulation may lead to hepatic and/or neuropsychiatric symptoms and to complex biochemical changes $(1,2)$. The recessive disease is due to mutations in the ATPase copper transporting beta polypeptide (ATP7B) gene on chromosome 13 (3). Diagnosed and treated at young age, WD has a favorable prognosis (4), but phenotypes are heterogeneous and may be late- or misdiagnosed (5).

With WD itself being a challenging diagnosis to the treating physician, hormonal dysfunction due to copper accumulation in endocrine glands rarely occurs and causes various symptoms that need precise interpretation followed by appropriate treatment.

Here we report a case with late-diagnosed WD and endocrine dysfunctions that resolved after copper chelation.

\section{Case presentation}

A 39-year-old Taiwanese female presented with jaundice, nausea, fatigue and writer's cramps that had evolved within few days without any triggering events. The medical history was unremarkable with two normal deliveries and healthy children without any specific family history. The patient had no siblings. The patient did not consume alcohol, used to drink green tea regularly (four to six cups per week), was on a vegan diet and used a hormonally active contraceptive coil (Levonorgestrel, Mirena $\left.{ }^{\circledR}\right)$ for approximately 3 years. No over the counter supplements, herbs or creams were used.

On examination she was jaundiced but had otherwise normal vital signs, the routine laboratory results are presented in Table 1. Abdominal ultrasound showed a compensated liver cirrhosis with portal hypertension and splenomegaly. A transcutaneous liver biopsy revealed no evidence for a nutritive toxic liver damage and other common hepatopathies. Hepatic parenchymal copper concentration revealed a high hepatic copper content of $1338 \mathrm{mg} / \mathrm{kg}$ (normal range: $10-35 \mathrm{mg} / \mathrm{kg}$ ). In addition, the serum ceruloplasmin was low $(10.7 \mathrm{mg} / \mathrm{dL}$, normal range: $25-60 \mathrm{mg} / \mathrm{dL}$ ), the $24-\mathrm{h}$ urinary copper excretion was increased with $708 \mu \mathrm{g}$ per day (normal range: 10-60 $\mu \mathrm{g} /$ day) and a coombs-negative hemolytic anemia was present (hemoglobin: $10.2 \mathrm{mg} / \mathrm{dL}$; lactate dehydrogenase (LDH): $385 \mathrm{U} / \mathrm{L}$ ). Thus, the diagnosis of Wilson's disease had to be made.

T2 MRI visualized increased densities in basal ganglia with the characteristic 'face of the giant panda' sign (Fig. 1). Genetic testing of the ATP7B gene revealed two heterozygous mutations: c.3140A $>\mathrm{T} \quad$ (p.Asp1047Val) on exon 14 and c.2828G>A (p.Gly943Asp) in exon 12
Table 1 Baseline laboratory and copper parameters.

\begin{tabular}{|c|c|c|}
\hline Parameter & Value & $\begin{array}{l}\text { Reference } \\
\text { values }\end{array}$ \\
\hline Sodium, $\mathrm{mmol} / \mathrm{L}$ & 136 & $135-145$ \\
\hline Potassium, mmol/L & 3.6 & $3.6-4.8$ \\
\hline Creatinine, mg/dL & 0.7 & $0.5-0.9$ \\
\hline Albumin, g/dL & 2.7 & $3.5-5.2$ \\
\hline Bilirubin, ng/dL & 0.7 & $<0.9$ \\
\hline Alanine transferase, U/L & 86 & $<35$ \\
\hline Gamma-glutamyltransferase, U/L & 211 & $<40$ \\
\hline Alkaline Phosphatase, U/L & 54 & $55-105$ \\
\hline Lactate dehydrogenase, U/L & 385 & $<248$ \\
\hline Leukocytes, /nL & 4.07 & $3.96-10.41$ \\
\hline Erythrocytes, /pL & 2.75 & $3.96-5.16$ \\
\hline Hemoglobin, g/dL & 10.2 & $11.6-15.5$ \\
\hline Hematocrit, \% & 31.1 & $34.6-45.3$ \\
\hline Thrombocytes, /nL & 93 & $176-391$ \\
\hline Prothrombin time, $\%$ & 41 & 70-130 \\
\hline International normalized ratio & 1.90 & \\
\hline Hepatic copper content, mg/kg & 1338 & $10-35$ \\
\hline Ceruloplasmin, mg/dL & 10.7 & $25-60$ \\
\hline $\begin{array}{l}\text { 24-hour urinary copper } \\
\text { excretion, } \mu g / \text { day }\end{array}$ & 708 & $10-60$ \\
\hline $\begin{array}{l}\text { 24-hour urinary copper excretion } \\
\text { after } 6 \text { months, } \mu \mathrm{g} / \text { day }\end{array}$ & 60 & $10-60$ \\
\hline
\end{tabular}

which were classified as pathogenic variants (class V) of the ACMG-AMP system (6). Both are missense variants, have separately been described as WD causing variants (HGMD Professional 2017.1) and are localized in the

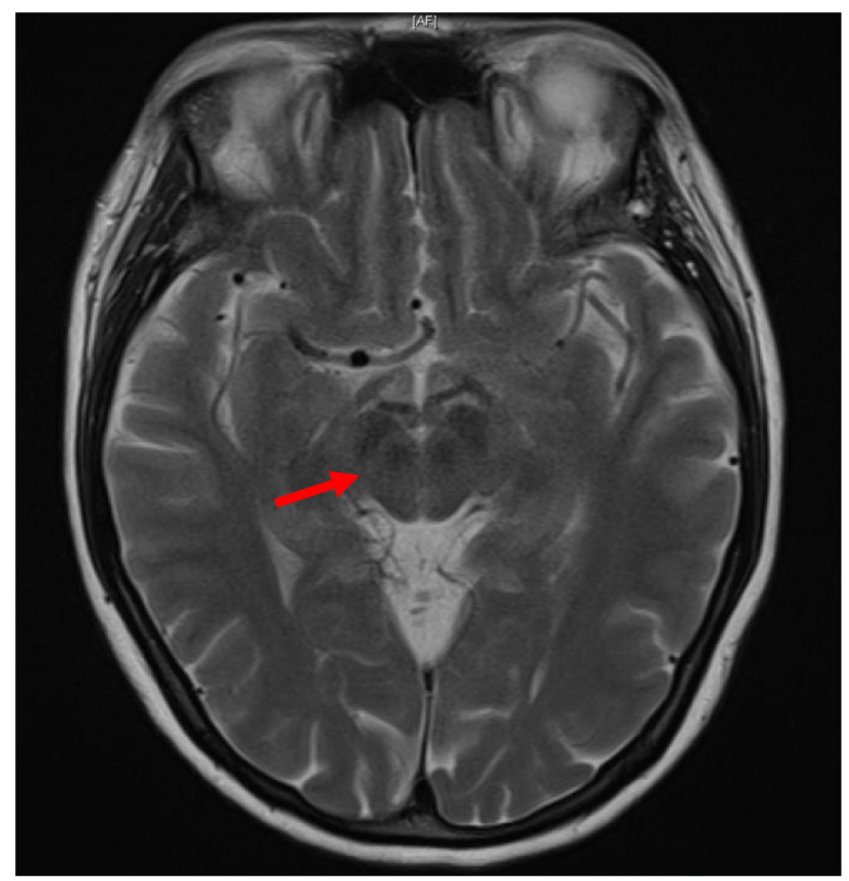

Figure 1

T2 magnetic resonance imaging (MRI) visualized increased densities in basal ganglia with the characteristic 'face of the giant panda'. 


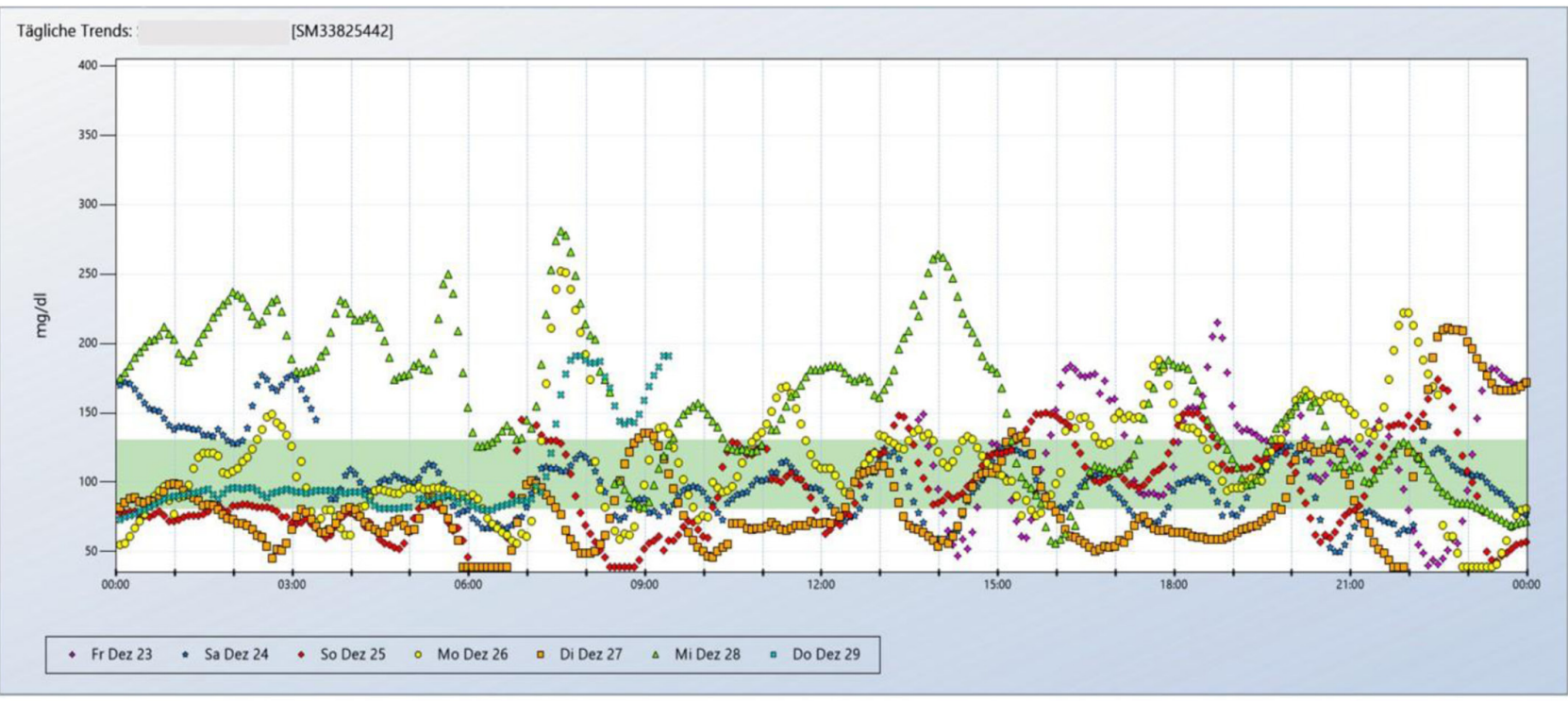

\section{Figure 2}

A subcutaneous continuous glucose monitoring (Dexcom G5 Mobile CGMS) revealed multiple hypoglycemic episodes but also transient hyperglycemia up to $>200 \mathrm{mg} / \mathrm{dL}$.

cation-transporting P-type ATPase domain. Although the variants are assumed to exist in trans, this needs to be confirmed by family testing.

Copper-chelation treatment was initiated by up titrating D-penicillamine and zinc with pyridoxine supplementation since penicillamine is known to inactivate pyridoxine. She was educated on medication compliance and stayed on a low-copper diet. She was also advised to quit the consumption of green tea since it is known to contain a high amount of copper. At this point, the patient had a stable disease with a Model for End-Stage Liver Disease (MELD) score of 15 obviating liver transplant considerations. The patient was evaluated for liver transplantation but not registered because of improving her state after initiation of cupper depleting therapy.

On follow-up, she reported fatigue and amenorrhea since the levonorgestrel containing coil had been removed around 3 months before. Additionally, she complained of meal-independent hypoglycemic symptoms, which were confirmed by blood glucose self-monitoring. After dietary adjustments, hypoglycemias as low as $50 \mathrm{mg} / \mathrm{dL}$ were confirmed on hospital admission. A subcutaneous continuous glucose monitoring (Dexcom G5 Mobile rtCGM) (Fig. 2) revealed multiple hypoglycemic episodes but also transient hyperglycemia up to $>200 \mathrm{mg} / \mathrm{dL}$.

Adrenal dysfunction was found explaining hypoglycemias: low baseline cortisol $(2.5 \mu \mathrm{g} / \mathrm{dL}$, normal range: $6.24-18.0 \mu \mathrm{g} / \mathrm{dL}$ ) and adrenocorticotropic hormone
(ACTH) (7.5 pg/mL, normal range: 7.2-63.6 pg/mL) confirmed by testing with $250 \mu \mathrm{g}$ cosyntropin. Cortisol rose to a subnormal peak after $60 \mathrm{~min}$ (basal: $3.1 \mu \mathrm{g} / \mathrm{dL}$, stimulated: $16.0 \mu \mathrm{g} / \mathrm{dL}$, normal range: $>18 \mu \mathrm{g} / \mathrm{dL}$ ) and adrenocorticotroph deficiency was diagnosed (Table 2).

In addition, she had thyrotroph insufficiency whereas the somatotroph function was not impaired. With decreased levels of luteinizing hormone (LH), folliclestimulating hormone (FSH) and estradiol we suspected gonadotroph insufficiency causing amenorrhea (Table 3).

Hypopituitarism was diagnosed involving the deficiency of the adrenocorticotroph, gonadotroph and thyrotroph axes. A sellar MRI ruled out pituitary adenoma but failed to show copper accumulation within the pituitary.

An oral glucose tolerance test was performed over $4.5 \mathrm{~h}$ with $75 \mathrm{~g}$ glucose to confirm diabetes mellitus and to rule out reactive postprandial hypoglycemia. Fasting glucose was normal, $2 \mathrm{~h}$ after oral glucose load it rose to $219 \mathrm{mg} / \mathrm{dL}$ and decreased to $61 \mathrm{mg} / \mathrm{dL}$ after $4.5 \mathrm{~h}$ with the patient showing hypoglycemic symptoms.

Substitution with hydrocortisone was started $(10 \mathrm{mg} /$ day), followed by L-thyroxine $50 \mu \mathrm{g} /$ day and copperchelating treatment continued. Within the following months, the patient's general condition improved considerably, and she did not observe any further hypoglycemias on glucose self-monitoring.

During follow-up, urinary copper excretion decreased to near-normal levels ( $<60 \mu \mathrm{g} /$ day $)$ and after 6 months 
Table 2 Results from the cosyntropin stimulation test (normal peak $>18 \mu \mathrm{g} / \mathrm{dL}$ after $60 \mathrm{~min}$ ).

\begin{tabular}{|c|c|c|}
\hline Parameter & Baseline & $\begin{array}{l}\text { After } \\
60 \mathrm{~min}\end{array}$ \\
\hline Cortisol, $\mu \mathrm{g} / \mathrm{dL}$ & 2.5 & 16 \\
\hline $\begin{array}{l}\text { Cortisol after copper-chelating } \\
\text { treatment, } \mu \mathrm{g} / \mathrm{dL}\end{array}$ & 11.0 & 31 \\
\hline
\end{tabular}

she reported menstrual cycles. The general condition further improved to full physical and mental fitness. After 48-h hydrocortisone cessation, another $250 \mu \mathrm{g}$ cosyntropin stimulation test was performed and revealed a normal cortisol peak (basal $11 \mu \mathrm{g} / \mathrm{dL}$, stimulated $31.0 \mu \mathrm{g} / \mathrm{dL}$, normal range $>18 \mu \mathrm{g} / \mathrm{dL}$ ). Thyreotroph function normalized as well with TSH and free thyroid hormones being within the normal range. Substitution of hydrocortisone and L-thyroxine was discontinued and well-tolerated with normalized glycemia.

Taken together hypopituitarism with hypoglycemia resulted from copper accumulation presumably in the pituitary or its regulating ganglia, since copper-chelating treatment normalized pituitary function.

\section{Investigation}

Tables 1 and 3 present the various tests carried out.

\section{Treatment}

Copper-chelating treatment for Wilson's disease:

D-penicillamine $600 \mathrm{mg}$ b.i.d.

Zinc 100 mg q.d.

Vitamin $B_{6}$ supplement

Pyridoxine $40 \mathrm{mg}$ q.d.
Endocrine treatment for hypopituitarism:

L-thyroxine $50 \mu \mathrm{g}$ q.d.

Hydrocortisone $5 \mathrm{mg}$ b.i.d.

\section{Outcome and follow-up}

Six months after initiation of copper-chelating therapy, urinary copper excretion decreased to near-normal levels of less than $60 \mu \mathrm{g}$ per day. By that time, the patient reported the return of regular menstruation cycles. Adrenal testing was normal and pituitary hormone levels also returned to normal indicating recovery of pituitary function. Subsequently, endocrine treatment was stopped. Genetic testing of the patient's children was recommended but not yet performed.

\section{Discussion}

Hypopituitarism with variable extent of endocrine dysfunction is a rare complication of WD. The underlying mechanism of hypopituitarism in WD remains elusive but pituitary copper deposition is most likely involved. Earlier serial studies in human WD described amenorrhea (7) and gonadotrophic dysfunction in males (8) that were put down to copper accumulation in the hypophysis. In addition, two case reports of young female WD patients illustrate signs and symptoms of pituitary dysfunction $(9,10)$. Previous reports of Asian patients also found pituitary dysfunction as part of WD in a Korean and a Chinese patient $(11,12)$ where one ATP7B mutation was shared with our case in the latter report. Taken together, we assume secondary neural damage to be the most likely cause of hypopituitarism in $\mathrm{WD}$, but further research is needed to clarify this.

Our patient had symptomatic hypoglycemia as initial and typical manifestation of secondary adrenal

Table 3 Endocrine laboratory parameters before and after copper-chelating treatment.

\begin{tabular}{l}
\hline Parameter \\
\hline Baseline cortisol, $\mu g / d L$ \\
ACTH, pg/mL \\
TSH, mU/L \\
$\mathrm{fT} 3, \mathrm{pg} / \mathrm{mL}$ \\
$\mathrm{fT} 4, \mathrm{ng} / \mathrm{dL}$ \\
Insulin-like growth factor $1, \mathrm{ng} / \mathrm{mL}$ \\
$\mathrm{LH}, \mathrm{IU} / \mathrm{L}$ \\
FSH, IU/IL \\
Estradiol, pg/mL \\
Prolactin, ng/mL \\
Insulin autoantibodies \\
Insulin/Glucose ratio during hypoglycemia
\end{tabular}

\begin{tabular}{c}
\hline Initial value \\
\hline 2.5 \\
7.5 \\
2.0 \\
2.1 \\
0.7 \\
121 \\
5.3 \\
7.6 \\
39 \\
16.2 \\
Negative \\
$<0.3$ \\
\hline
\end{tabular}

\begin{tabular}{c}
\hline Post-treatment \\
\hline 11.0 \\
8.4 \\
2.4 \\
2.6 \\
1.0 \\
107 \\
3.5 \\
5.4 \\
66
\end{tabular}

\begin{tabular}{c}
\hline Reference values \\
\hline $6.24-18$ \\
$7.2-63.6$ \\
$0.27-4.2$ \\
$2.21-4.43$ \\
$0.82-1.77$ \\
$106-256$ \\
$2-10$ \\
$4-9$ \\
$45-95$ \\
$6.0-29.9$ \\
\end{tabular}


insufficiency, but also high glucose levels confirmed by $75 \mathrm{~g}$ oral glucose testing and continuous blood glucose monitoring. Another young female with WD also had presented with hypoglycemic insulin dysregulation (10). Since WD results from copper deposits in various tissues, an endocrine pancreas dysfunction may ensue and complement hepatic insulin resistance $(13,14,15)$. In our patient diabetes was no longer detectable after copper chelation.

In conclusion, this case illustrates an association between endocrine dysfunction and WD. Physicians need to be alert since patients with $\mathrm{WD}$ can be oligosymptomatic. Copper-chelating treatment may lead to endocrine recovery. Vice versa WD should be considered as a possible cause of idiopathic hypopituitarism.

\section{Declaration of interest}

The authors declare that there is no conflict of interest that could be perceived as prejudicing the impartiality of the research reported.

\section{Funding}

This research did not receive any specific grant from any funding agency in the public, commercial or not-for-profit sector.

\section{Author contribution statement}

$\mathrm{N} \mathrm{D}$ and $\mathrm{M}$ W were the patients' named physicians. N D, V T M, M M and $\mathrm{M}$ W contributed to acquisition of data, analysis and interpretation of data. N D, V T M and K B drafted the article. C L and S Z contributed to the discussion and revised the manuscript for content.

\section{References}

1 Frommer DJ. Defective biliary excretion of copper in Wilson's disease. Gut 197415 125-129. (https://doi.org/10.1136/gut.15.2.125)

2 Chowrimootoo GF, Ahmed HA \& Seymour CA. New insights into the pathogenesis of copper toxicosis in Wilson's disease: evidence for copper incorporation and defective canalicular transport of caeruloplasmin. Biochemical Journal 1996315 851-855. (https://doi. org/10.1042/bj3150851)
3 Ferenci P. Regional distribution of mutations of the ATP7B gene in patients with Wilson disease: impact on genetic testing. Human Genetics 2006120 151-159. (https://doi.org/10.1007/s00439-0060202-5)

4 Bruha R, Marecek Z, Pospisilova L, Nevsimalova S, Vitek L, Martasek P, Nevoral J, Petrtyl J, Urbanek P, Jiraskova A, et al. Long-term follow-up of Wilson disease: natural history, treatment, mutations analysis and phenotypic correlation. Liver International 201131 83-91. (https://doi.org/10.1111/j.1478-3231.2010.02354.x)

5 Trocello JM, Broussolle E, Girardot-Tinant N, Pelosse M, Lachaux A, Lloyd C \& Woimant F. Wilson's disease, 100 years later. Revue neurologique 2013169 936-943. (https://doi.org/10.1016/j. neurol.2013.05.002

6 Richards S, Aziz N, Bale S, Bick D, Das S, Gastier-Foster J, Grody WW, Hegde M, Lyon E, Spector E, et al. Standards and guidelines for the interpretation of sequence variants: a joint consensus recommendation of the American College of Medical Genetics and Genomics and the Association for Molecular Pathology. Genetics in Medicine 201517 405-424. (https://doi.org/10.1038/gim.2015.30)

7 Kim JM, Ko SB, Kwon SJ, Kim HJ, Han MK, Kim DW, Cho SS \& Jeon BS. Ferrous and ferric iron accumulates in the brain of aged Long-Evans Cinnamon rats, an animal model of Wilson's disease. Neuroscience Letters 2005382 143-147. (https://doi.org/10.1016/j. neulet.2005.03.003)

8 Quemeneur AS, Trocello JM, Ea HK, Ostertag A, Leyendecker A, Duclos-Vallée JC, de Vernejoul MC, Woimant F \& Lioté F. Bone status and fractures in 85 adults with Wilson's disease. Osteoporosis International 201425 2573-2580. (https://doi.org/10.1007/s00198014-2806-2)

9 Frydman M, Kauschansky A, Bonne-Tamir B, Nassar F \& Homburg R. Assessment of the hypothalamic-pituitary-testicular function in male patients with Wilson's disease. Journal of Andrology 199112 180-184.

10 Erkan T, Aktuglu C, Gulcan EM, Kutlu T, Cullu F, Apak H \& Tümay GT. Wilson disease manifested primarily as amenorrhea and accompanying thrombocytopenia. Journal of Adolescent Health 2002 31 378-380. (https://doi.org/10.1016/s1054-139x(02)00355-5)

11 Krysiak R, Handzlik-Orlik G \& Okopien B. Endocrine symptoms as the initial manifestation of Wilson's disease. Yale Journal of Biology and Medicine 201285 249-254.

12 Lee HW, Kang JD, Yeo CW, Yoon SW, Lee KJ \& Choi MK. Hypopituitarism presenting as adrenal insufficiency and hypothyroidism in a patient with Wilson's disease: a case report. Journal of Korean Medical Science 201631 1345-1348. (https://doi. org/10.3346/jkms.2016.31.8.1345)

13 Zhang QJ, Xu LQ, Wang C, Hu W, Wang N \& Chen WJ. Four-year follow-up of a Wilson disease pedigree complicated with epilepsy and hypopituitarism: case report with a literature review. Medicine 201695 e5331. (https://doi.org/10.1097/MD.0000000000005331)

14 Sulochana G \& Viswanathan J. Wilson's disease with associated diabetes mellitus presenting as renal tubular acidosis. Journal of the Association of Physicians of India 198230 405-407.

15 Baig NA, Herrine SK \& Rubin R. Liver disease and diabetes mellitus. Clinics in Laboratory Medicine 200121 193-207.

Received in final form 14 September 2020

Accepted 8 October 2020 